\title{
An Anglo-American Comparison of the Prevalence of Bronchitis
}

\author{
D. D. REID,* M.D., D.SC., M.R.C.P. ; D. O. ANDERSON, † M.D., F.R.C.P.ED. ; B. G. FERRIS, $\ddagger$ M.D., F.A.C.P.M. ; \\ C. M. FLETCHER,§ C.B.E., M.D., F.R.C.P.
}

Brit. med. F., 1964, 2, 1487-1491

Several intriguing differences in the reported mortality experience of middle-aged men in the United States and in England and Wales have stimulated speculation about their reality and their explanation (Reid, 1960). Roughly speaking, while the white North American male aged 45 to 54 is twice as likely to die from ischaemic heart disease as his contemporary in England and Wales, the latter suffers a twofold excess in mortality from lung cancer and perhaps a fivefold excess in the risk of death from the broad group of diseases comprising chronic bronchitis, emphysema, and bronchiectasis. Discrepancies in diagnostic concepts and customs in death certification could explain some of these differences in reported mortality, but the American members of the Joint U.S.-U.K. Board set up by the United States Public Health Service National Heart Council reported after a tour of British hospitals that although such discrepancies certainly existed they could not explain all of the British excess in serious respiratory disease (Meneely et al., 1960).

Because of the clinical complexity of the terminal condition in chronic cardio-respiratory disease, there is a clear need for surveys in both countries of the prevalence of earlier forms of respiratory disorder in which the patient's condition can be precisely defined and specifically related-for example, to his environment at home or at work and to his personal habits. In this way Anglo-American differences in experience of respiratory disease might be denied or confirmed. Since it is unlikely that genetic influences are here important, a finding of a real disparity between morbidity levels associated with differences in environment or personal habits could point to major factors in the causation of chronic lung disease and thus indicate possible preventive measures.

We here report a comparison between two surveys where the results of the use of standardized clinical methods give a clearer indication of the differences in respiratory morbidity than any other survey results yet available.

In October 1961 the British College of General Practitioners reported the results of a survey directed by their Research Committee on Respiratory Diseases. This study involved the interrogation and examination of a random sample of men and women aged 40 to 64 drawn from the practice lists of 92 doctors working in urban and country areas of Britain. The doctors concerned used a standard questionary on respiratory symptoms and history as well as on occupation, residence, and smoking habits and the Wright peak-flow meter as a measure of lung function. The same questionary (from which the Medical Research Council version was evolved) was later used by Ferris and Anderson (1962) in a similar survey of a probability sample of residents in Berlin, New Hampshire, a manufacturing centre of pulp and paper products in northern New England (population 17,821 in 1960). The population was not representative of that of the United States in general: approxi-

* Professor of Epidemiology, London School of Hygiene and Tropical Medicine.

† Assistant Professor of Medicine and Preventive Medicine, University of British Columbia, Vancouver, B.C.

‡ Associate Professor of Environmental Health and Safety, Harvard School of Public Health.

$\$$ Reader in Clinical Epidemiology, Postgraduate Medical School of London. mately $20 \%$ of the total population were foreign-born, the largest single group (about 15\%) being French-Canadian. Ferris and Anderson obtained their samples from an up-todate head-tax roll prepared by a yearly census. The sampling ratio which they used was $1: 10$ for persons 25 to 54 years and $1: 5$ for persons 55 to 74 years of age. The age range covered was wider than in the College of General Practitioners study, but the detailed findings for men and women aged 45 to 64 have been extracted to make possible a strict comparison according to age and sex. The Wright peak-flow meter was one of the tests employed in this inquiry to measure the degree of ventilatory impairment.

\section{Method of Analysis}

Besides age and sex, other variables are especially significant in geographic comparisons of the prevalence of respiratory disease. Smoking habits, in terms of both amount of tobacco smoked and the manner of smoking it, are clearly important ; and the results are divided accordingly into non-smokers, those who have given up the habit (ex-smokers), those cigarette smokers smoking either less or equal to 20 cigarettes a day in Berlin, New Hampshire, and 25 in Britain or more than those amounts, and those using cigars and pipes either alone or in addition to cigarettes. These latter groups have been categorized as "pipe and/or cigar smokers" and " mixed smokers" respectively.

The data on symptoms have been set out in two ways. First, the frequency of individual items-for example, winter cough or breathlessness on the level-is tabulated by age and sex in the two studies. The prevalence rates of the more important of these items are then given for Berlin and the rural areas, small towns, and large urban regions of Britain. In this way it is possible, after making appropriate adjustments for differences in smoking habits, to relate the American experience to the context of the well-known rural-urban gradient within Britain.

Certain of these defined items can be combined to form standard syndromes indicating chronic respiratory disorder. They were grouped in two ways to provide what we refer to as the "simple" and "complex" syndromes. The simple syndrome is that used by Ferris and Anderson (1962) whereby patients were classified as suffering from a "simple" form of "chronic bronchitis" when answering "Yes" to these questions :

\footnotetext{
" Do you usually bring up phlegm from your chest (not from the back of your nose) ?" and/or

"Do you bring up any phlegm at all on getting up (or first thing in the morning) in winter?" and

"How long have you had this cough and/or phlegm-[ 3 years or more?]"
}

In the British study this question was phrased- " 2 years or more?", but there is evidence that this difference is immaterial (Fletcher et al., 1959).

From the College of General Practitioners (1961) report has been taken the complex syndrome of bronchitic symptoms 
defined as the presence of positive answers to the three questions :

"Do you bring up any phlegm at all on getting up or first thing in the morning in winter";

"Do you get bouts of cough and phlegm lasting for at least three weeks each winter and for more than two winters ?"; and

"Do you have to walk slower than people of your own age on the level because of breathlessness?"

Clearly, the "complex" syndrome implies a more serious form of chronic respiratory illness with symptoms indicating recurrent infection and airways' obstruction. The prevalence rates of both syndromes have been related to age, sex, smoking habits, and place of residence. Wright peak-flow-meter results are given for subjects in these clinical groups divided according to their smoking habits.

\section{Results}

Table I shows the distribution of smoking habits in these two samples. The proportion of non-smokers in those who have never smoked more than an occasional cigarette is appreciably higher in the American group ; but there are also among them relatively more heavy cigarette smokers. Slightly more (64\% to $60 \%$ ) of the American women are non-smokers, and fewer of the British women are heavy smokers; but the differences between the two groups of women are much less than those for the men. These findings agree quite well with those based on national surveys (Hammond and Garfinkel, 1961 ; Todd, 1963), so that in one respect at least the experience of these small samples may be applied more widely.

TABLE I.-Comparison of Smoking Habits

\begin{tabular}{|c|c|c|c|c|c|c|c|}
\hline & \multirow[b]{2}{*}{ No. } & \multicolumn{6}{|c|}{ Percentage } \\
\hline & & $\begin{array}{l}\text { Non- } \\
\text { smoker }\end{array}$ & $\begin{array}{c}\text { Ex- } \\
\text { smoker }\end{array}$ & $\begin{array}{l}\text { Present* } \\
\text { Cigarettes } \\
\text { I }\end{array}$ & $\mid \begin{array}{c}\text { Present } \\
\text { Cigarettes } \\
\text { II }\end{array}$ & $\begin{array}{l}\text { Pipe/ } \\
\text { Cigar }\end{array}$ & $\begin{array}{l}\text { Mixedt } \\
\text { Smoker }\end{array}$ \\
\hline \multicolumn{8}{|c|}{ Males 45-64 } \\
\hline $\begin{array}{l}\text { U.S. } \\
\text { U.K. }\end{array}$ & $\begin{array}{l}244 \\
638\end{array}$ & $\begin{array}{r}14 \\
6\end{array}$ & \begin{tabular}{l|}
14 \\
19
\end{tabular} & $\begin{array}{l}26 \\
\mathbf{4 7}\end{array}$ & $\begin{array}{r}21 \\
9\end{array}$ & $\begin{array}{r}10 \\
8\end{array}$ & $\begin{array}{l}15 \\
11\end{array}$ \\
\hline \multicolumn{8}{|c|}{ Females 45-64 } \\
\hline $\begin{array}{l}\text { U.S. } \\
\text { U.K. }\end{array}$ & $\begin{array}{l}302 \\
620\end{array}$ & $\begin{array}{l}64 \\
60\end{array}$ & $\begin{array}{l}6 \\
9\end{array}$ & \begin{tabular}{|l}
24 \\
30
\end{tabular} & $\begin{array}{l}6 \\
1\end{array}$ & 二 & - \\
\hline
\end{tabular}

\begin{tabular}{|c|c|c|c|c|c|c|c|c|}
\hline \multirow{3}{*}{ Age-group: } & \multicolumn{4}{|c|}{ Males } & \multicolumn{4}{|c|}{ Females } \\
\hline & \multicolumn{2}{|c|}{ U.S. } & \multicolumn{2}{|c|}{ U.K. } & \multicolumn{2}{|c|}{ U.S. } & \multicolumn{2}{|c|}{ U.K. } \\
\hline & $45-54$ & $55-64$ & $45-54$ & $55-64$ & $45-54$ & $55-64$ & $45-54$ & $55-64$ \\
\hline No. in group: & (83) & (161) & (320) & (318) & (121) & (181) & (315) & (305) \\
\hline $\begin{array}{l}\text { Cough on rising in } \\
\text { winter } \ddot{3} \\
\text { Cough during day in }\end{array}$ & 36 & 41 & 47 & 53 & 15 & 15 & 20 & 23 \\
\hline $\begin{array}{ll}\text { winter } & \ldots \\
\text { Usual phlegm } & \end{array}$ & $\begin{array}{l}18 \\
33\end{array}$ & $\begin{array}{l}22 \\
32\end{array}$ & $\begin{array}{l}18 \\
35\end{array}$ & $\begin{array}{l}24 \\
42\end{array}$ & $\begin{array}{l}10 \\
15\end{array}$ & $\begin{array}{l}10 \\
14\end{array}$ & $\begin{array}{l}10 \\
13\end{array}$ & $\begin{array}{l}15 \\
20\end{array}$ \\
\hline $\begin{array}{l}\text { Phlegm on rising in } \\
\text { winter } \\
\text { Phlegm during day in }\end{array}$ & 33 & 32 & 39 & 48 & 12 & 13 & 16 & 21 \\
\hline 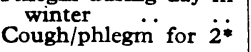 & 16 & 17 & 16 & 20 & 7 & 8 & 5 & 10 \\
\hline $\begin{array}{l}\text { years or more } \\
\text { Bouts of cough and }\end{array}$ & 45 & 47 & 43 & 52 & 22 & 17 & 18 & 27 \\
\hline $\begin{array}{l}\text { phlegm } 3 \text { weeks more } \\
\text { than } 2^{*} \text { winters } \\
\text { Breathlessness-Grade }\end{array}$ & 13 & 13 & 22 & 28 & 7 & 9 & 13 & 15 \\
\hline $\begin{array}{ll}\text { II or more } & \\
\text { Chest wheezy } & \text { most }\end{array}$ & 6 & 11 & 9 & 25 & 21 & 19 & 10 & 20 \\
\hline $\begin{array}{l}\text { days or nights } \\
\text { Weather affecting chest } \\
\text {-making more }\end{array}$ & 11 & 10 & 8 & 15 & 4 & 4 & 4 & 5 \\
\hline "Cheathless illness"; in past & 16 & 15 & 16 & 24 & $19 t$ & $14 t$ & 9 & 16 \\
\hline 3 years $\quad \ldots \quad \ldots$ & 6 & 6 & 25 & 34 & 14 & 16 & 21 & 31 \\
\hline
\end{tabular}

3 in U.S.

t These rates are higher than originally reported (Ferris and Anderson, 1962), $t$ These rates are higher than
because of an error in tabulation.
Table II shows, according to age and sex, the relative frequency in the two countries of certain specific symptoms, including those used to define either the "simpler" or the "complex" forms of bronchial disorder. The most striking disparity is between the marked increase in frequency of symptoms in older British men, and to a much less degree in British women, and the trivial differences between younger and older agegroups in both American men and women in middle life. From this list certain responses have been selected for inclusion in Fig. 1 as representing the main symptoms of respiratory disease used to describe " chronic bronchitis" in the College of General Practitioners report and the Berlin, New Hampshire, reports. The proportional increase in the frequency of these symptoms in the older age-group over the levels of subjects aged 45 to 54 is obvious in both males and females in Britain; but it is markedly absent in the American population of both sexes. While observer variation might account for differences in the level of symptom frequencies reported, it cannot explain these disparities in age-trend within each survey.

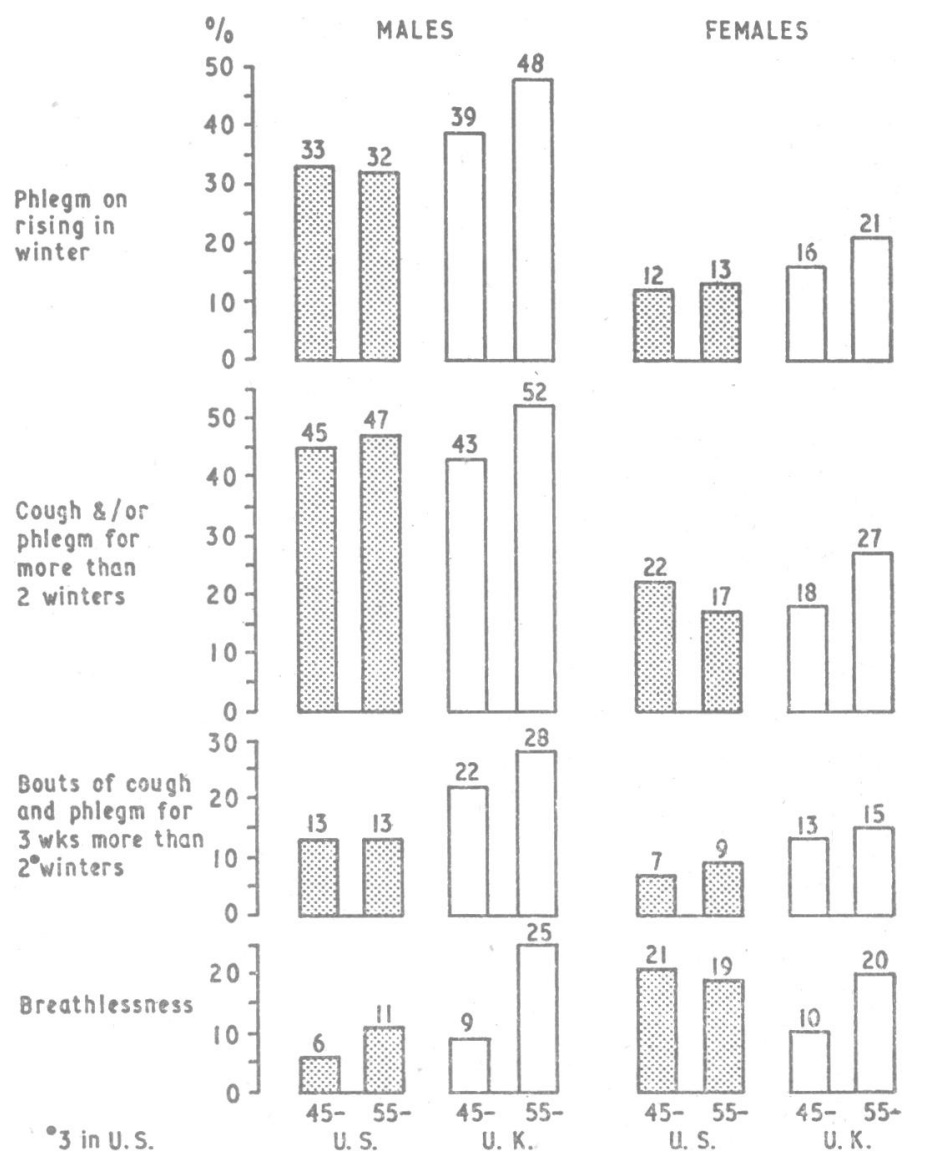

FIg. 1.-Age trends in symptom prevalence.

The American data on these symptoms in both sexes can be set out as in Fig. 2 against the age-standardized frequency rates for rural areas, small and large towns, and cities in the United Kingdom. The American levels for men tend to lie around the rate for British rural areas. The pattern among women is less distinct, but, except for breathlessness, not discordant. The difficulty of eliciting histories of breathlessness consistently in the two sexes has been discussed in the earlier reports of the Berlin, New Hampshire, survey.

The results can be looked at in a different way by combining some of these individual items into defined syndromes according to the conventions already described. Fig. 3 gives the results of these combinations in the four age and sex groups in the two countries. Under the age of 55, the British excess in the frequency of both types of "bronchitis" is small; but above that age the British excess becomes quite apparent in 
respect of the milder or simple respiratory disturbance defined by Ferris and Anderson and very pronounced in both sexes in the more serious complex disability described in the College of General Practitioners report.

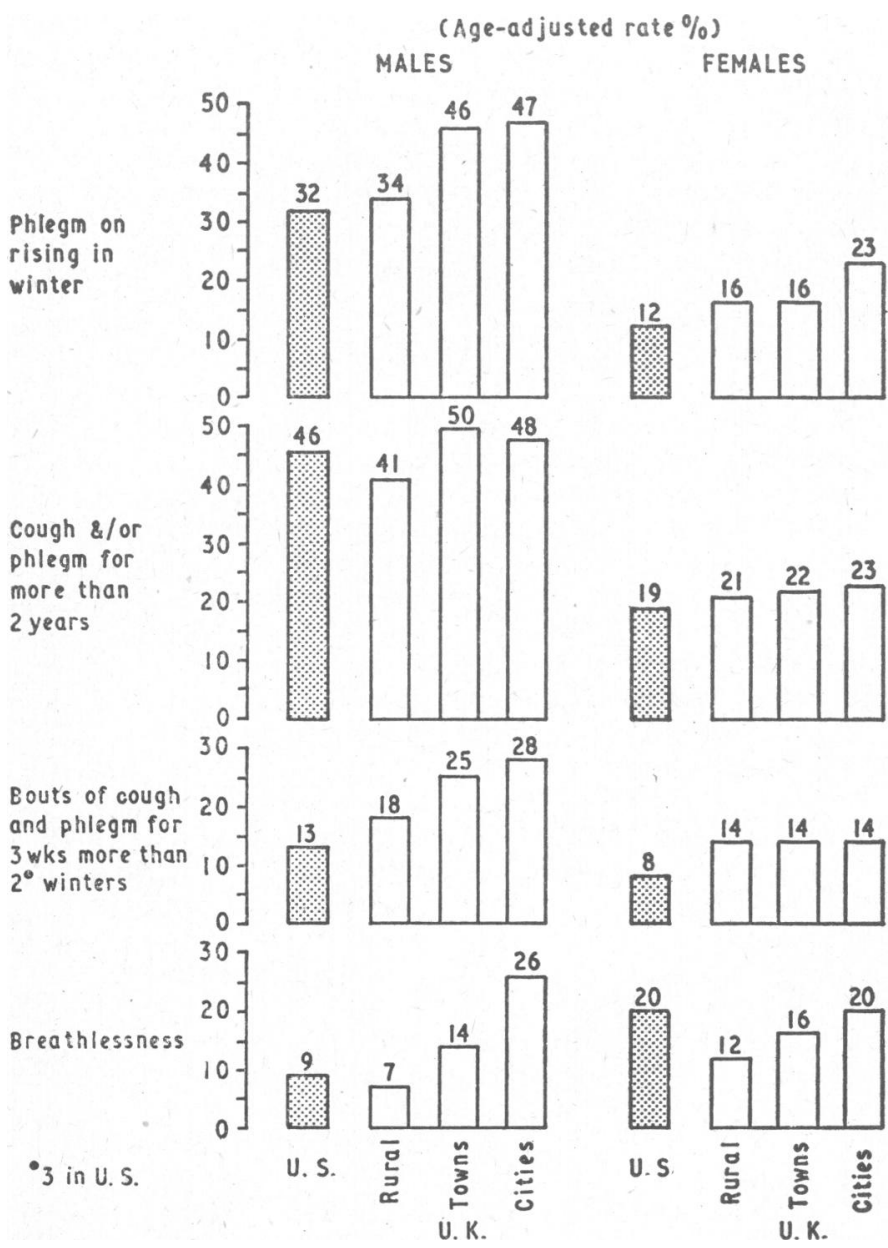

FIG. 2.-American experience and British rural-urban trends in symptom prevalence.

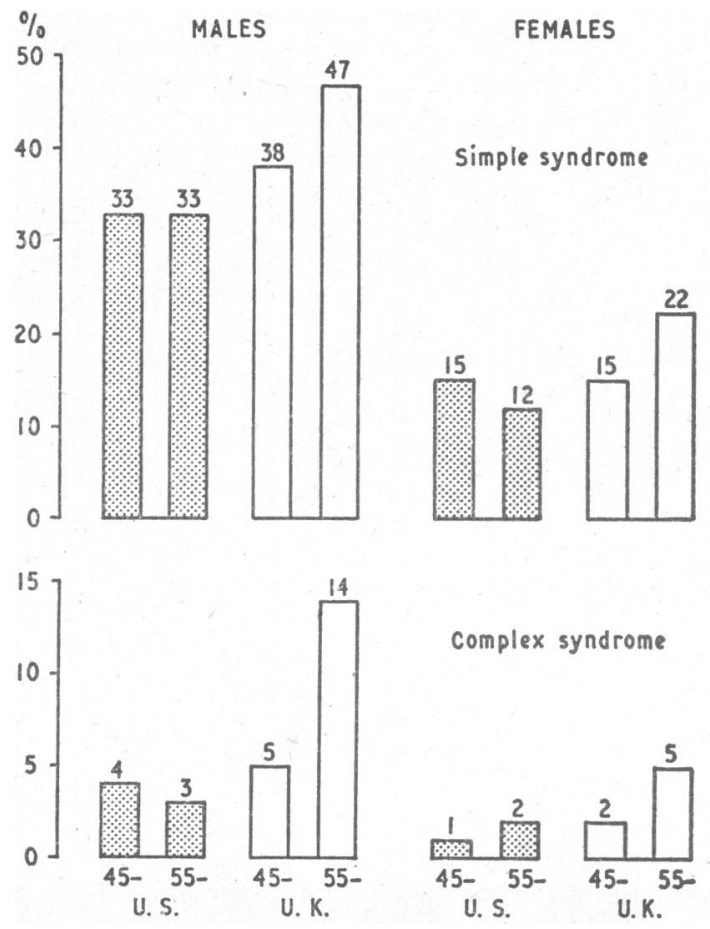

Fig. 3.-Comparison of syndrome frequency.
Prevalence rates for the two syndromes in relation to the smoking history among men aged 45 to 64 are set out in Fig. 4 . The small group of mixed smokers is not included. Particularly for the simpler syndrome, the contrast between nonsmokers and cigarette smokers is clearly evident, while those smoking pipes or cigars have generally lower rates than those smoking cigarettes. The rates for those who have given up smoking tend to fall, in both countries, between the nonsmoking and cigarette-smoking groups in the same country. These results are consistent with previously reported experience (Higgins, 1957). The higher rates for British ex-smokers may be due to the presence of symptoms being a more frequent

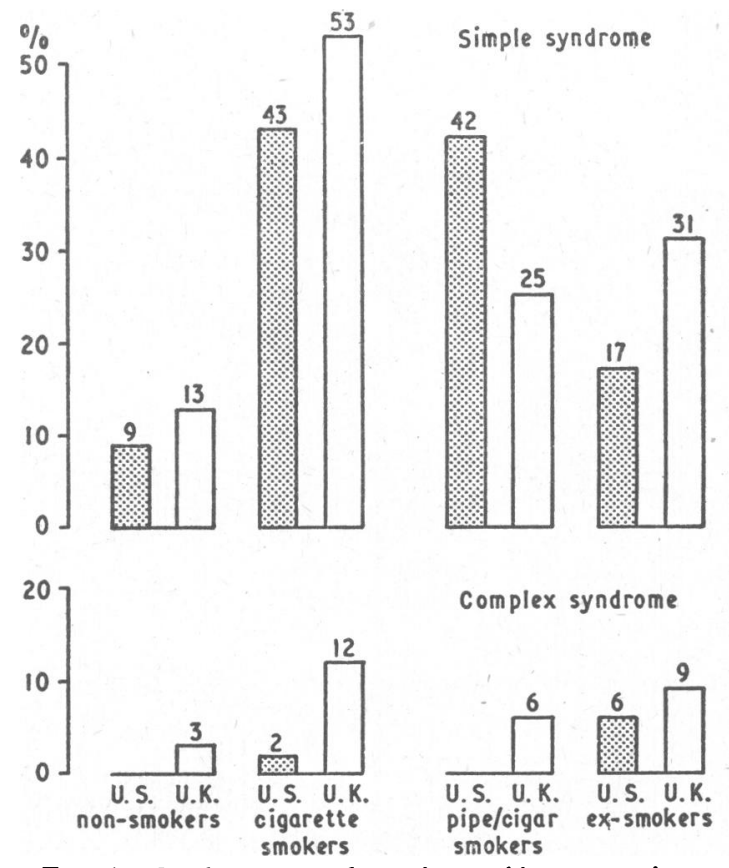

Fig. 4.-Syndrome prevalence in smoking categories.

cause of giving up the habit in Britain. Of greater significance from the point of view of international comparison, however, is the fact that quite consistently the British rates of both types of respiratory disorder are higher within each smoking category. It is also noteworthy that in the non-smoking groups the British suffer consistently, if not remarkably, more from both the simple and complex syndromes.

Geographic differences in smoking habits can be taken into account in another way. In their earlier paper Ferris and Anderson describe how they interrogated their subjects about cigarette consumption at different periods of their lives and then estimated tobacco consumption in terms of the number of packets of 20 cigarettes smoked up to the present age. Here we have used the more limited information available in the British surveys by multiplying the current level of consumption by the number of years since the habit was begun. (Hand-rolled cigarettes were assumed to contain $95 \mathrm{mg}$. of tobacco in the United States and $100 \mathrm{mg}$. in the United Kingdom.). The same estimates have been made for both past and present cigarette smokers in the British sample and age- and sex-specific rates calculated for each consumption group. These British rates have then been applied as standard rates to the American sample classified in the same way to compute age- and smokingadjusted morbidity rates which take into account the differences in cigarette consumption between the two populations. Fig. 5 shows these age- and smoking-adjusted rates in Berlin, New Hampshire, and the rural areas and small and large towns of Britain for both the simple and complex syndromes. The geographic variation in the frequency of the simple syndrome is not great, although the American rate is, like the rural British rate, rather below the urban levels in both sexes. For the complex syndrome, however, the rural-urban gradient is 
marked, especially in men, and the American rates are identical with those in rural Britain.

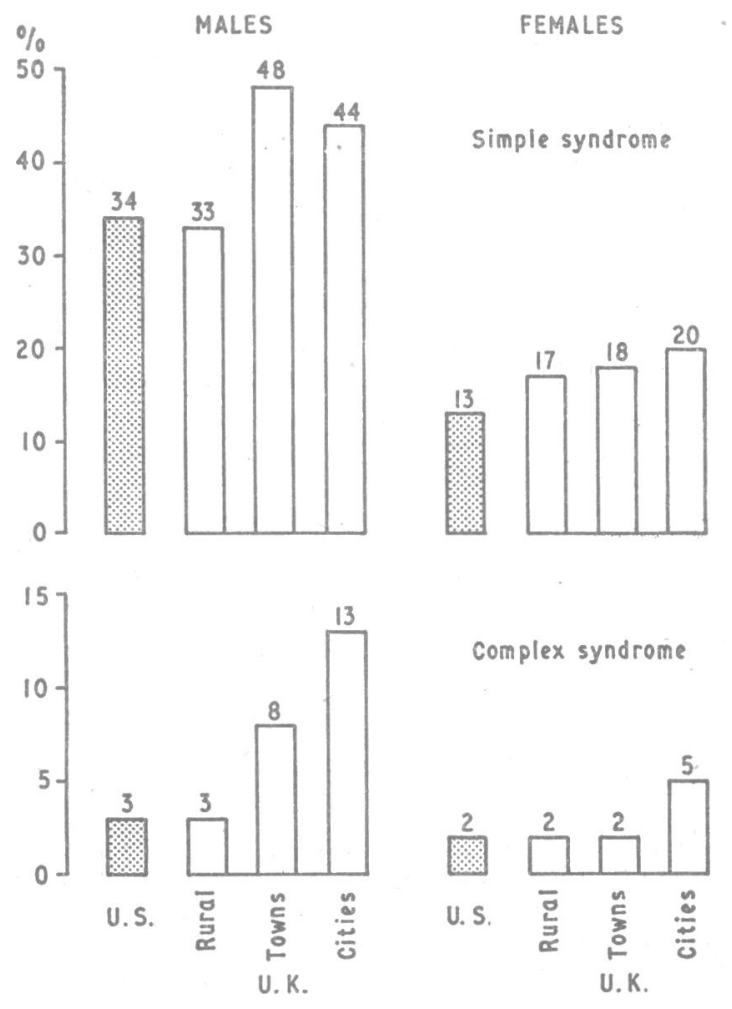

Fig. 5.-Prevalence rates standardized for age and lifetime cigarette consumption.

A cross-check on the validity of these observations based on questions about symptoms can be gained by reference to the more objective evidence of lung-function test results. Table III sets out by age, sex, and smoking habits the results of using the Wright peak-flow meter as a measure of ventilatory impairment. It should be noted that no close standardization of method, as by exchange of observers, was practicable, and since no height or weight measurements were taken by the British practitioners adjustment for stature was impossible. Nevertheless, there is a surprisingly close agreement between the large groups of women non-smokers in the two countries, particularly as it is likely that part of the American superiority in peak-flow levels may reflect a greater mean height.

As already noted in discussion in the earlier reports of these studies (Anderson and Ferris, 1962), cigarette smokers have lower mean flow values than non-smokers. Deterioration in performance with ageing within each smoking and sex group is about equally marked in the two countries, and there is no consistent suggestion that, on average, the British deteriorate more quickly at this time of life. It could be, of course, that these findings refer to survivor populations from whom, particularly in Britain, the respiratory invalids have already been removed by premature death. Table IV, which sets out the results according to clinical state, might give substance to that view. While those free from either the milder or the more serious forms of bronchitis differ relatively little, the British with the severer type of illness are in functional terms, relative to their unaffected compatriots, much more disabled than the Americans with similar symptoms. The numbers on which this impression is based are, however, small and the differences are not technically significant.

\section{Discussion}

The use of a standard questionary and the measuring of ventilatory impairment by a simple test such as the Wright peak-flow meter have enabled us to make a useful comparison between surveys of respiratory disorder conducted by different groups of observers in different countries. Equally obvious is the need for and the collection of relevant data on age and sex, and particularly on smoking habits. In the latter case the manner as well as the amount of smoking must be specified. In both countries the cigarette smokers seemed to be more adversely affected than those smoking either pipes or cigars. This contrast has already been observed by Olsen and Gilson (1960) in Denmark. The clinical data elicited by the questionary can be used in two ways. Each individual item, such as the frequency of cough on rising in the winter, can be looked at to see how the level varies-for example, between rural and urban areas. From this viewpoint the degree of difference between experience of respiratory symptoms by the inhabitants in the American town and that of their British contemporaries depends on the severity of the symptoms concerned. For the commoner (and milder) disturbances, such as morning cough and phlegm, the Americans differ little from people living in rural Britain, who in turn, in this respect at least, differ little from those in British towns and cities. More serious symptoms, on the other hand, such as disabling breathlessness, are again about as frequent in Berlin, U.S.A., as in British rural areas, but are much more frequent in British cities. Moreover, a striking feature of this particular American experience is the absence of the steep rise in bronchitic morbidity with increasing age which has already been pointed out as a characteristic of the disease in chronic bronchitis in the urban areas of Britain (Reid and Fairbairn, 1958).

Geographic comparisons can be freed from problems of local idiosyncrasies in diagnostic customs and standards by combining specified clinical items into "standard syndromes." In this study the different frequencies of two such groupings reflected the trends already noted; for while the prevalence of

TABLE III.-Mean Peak-flow Rates (litres/min.) (Numbers in Groups Within Parentheses)

\begin{tabular}{c|c|c|c|c|c|c|c|c}
\hline \multirow{3}{*}{ Age-group } & \multicolumn{9}{|c|}{ Males } & \multicolumn{4}{c}{ Females } \\
\cline { 2 - 7 } & \multicolumn{2}{|c|}{ Non-smokers } & \multicolumn{2}{c}{ Present Smokers } & \multicolumn{2}{c}{ Non-smokers } & \multicolumn{2}{c}{ Present Smokers } \\
\cline { 2 - 8 } & U.S. & U.K. & U.S. & U.K. & U.S. & U.K. & U.S. \\
\hline $45-54$ & $464(14)$ & $467(23)$ & $440(59)$ & $415(237)$ & $350(61)$ & $323(171)$ & $346(51)$ & $316(110)$ \\
$55-64$ & $455(19)$ & $438(17)$ & $390(117)$ & $365(223)$ & $304(133)$ & $300(190)$ & $305(40)$ & $294(75)$ \\
\hline Total & $459(33)$ & $455(40)$ & $406(176)$ & $391(460)$ & $318(194)$ & $311(361)$ & $328(91)$ & $307(185)$ \\
\hline
\end{tabular}

TABLE IV.-Mean Peak-flow Rates (litres/min.) Ages 45-64 (Numbers in Groups Within Parentheses)

\begin{tabular}{|c|c|c|c|c|c|c|c|c|}
\hline & \multicolumn{4}{|c|}{ Males } & \multicolumn{4}{|c|}{ Females } \\
\hline & \multicolumn{2}{|c|}{ Non-smokers } & \multicolumn{2}{|c|}{ Present Smokers } & \multicolumn{2}{|c|}{ Non-Smokers } & \multicolumn{2}{|c|}{ Present Smokers } \\
\hline & U.S. & U.K. & U.S. & U.K. & U.S. & U.K. & U.S. & U.K. \\
\hline $\begin{array}{l}\text { Simple syndrome } \\
\text { Complex syndrome } \\
\text { Others }\end{array}$ & $\begin{array}{l}583(3) \\
447(30) \\
(-)\end{array}$ & $\begin{array}{l}330(5) \\
350(1) \\
473(35)\end{array}$ & $\begin{array}{l}353(71) \\
370(5) \\
438(105)\end{array}$ & $\begin{array}{r}356(217) \\
273(43) \\
422(243)\end{array}$ & $\begin{array}{l}300(18) \\
250(3) \\
320(176)\end{array}$ & $\begin{array}{l}264(37) \\
239(9) \\
316(324)\end{array}$ & $\begin{array}{l}345(21) \\
450(2) \\
323(70)\end{array}$ & $\begin{array}{l}286(56) \\
233(6) \\
317(129)\end{array}$ \\
\hline
\end{tabular}


a syndrome of " simple bronchitis" (in effect chronic phlegmproduction) was equally common in Berlin and Britain, the complex syndrome, also involving breathlessness and repeated chest illness, was much more frequent in the British population, particularly in men aged 55 and over. Although women display similar trends, the differences, like the differences in female British and American death rates from chronic respiratory disease, are not nearly so dramatic.

In general, the trends in the results, in terms of averages, of the application of the peak-flow meter test agree with the general impression of more severe disease in the older British male; but the evidence is slender. More serious impairment, however, is clearly commoner in the British male group. Indeed, all these results underline the fact that it is at the extremes of the range of respiratory function that the difference between two populations is most readily detected.

It is tempting to speculate on the explanation of these tentative findings. The placing of this one American town in relation to the rural-urban gradient in British experience and the rather higher rates of disease in British non-smokers might suggest that some factor in British urban life, such as air pollution, was accentuating the effect of smoking on respiratory malfunction. This preliminary inquiry cannot suggest the nature of that factor with any precision, for no account has been taken of the social-class background which appears so decisively in sickness and death rates from bronchitis in Britain. It has, however, demonstrated the potential of such comparisons and emphasized the need for their wider and more sophisticated application.

\section{Summary}

The reported British excess in bronchitic morbidity has been studied by comparing the results of field surveys carried out in various parts of this country and in one town in the United States. In both, similar respiratory-symptom questionaries and a simple lung-function test (the Wright peak-flow meter) were used.
The prevalence of "simple bronchitis"-that is, chronic phlegm-production-differs little between the American towns and the rural and urban areas of Britain; and its relation to cigarette smoking in particular is obvious in the results from both countries. On the other hand, "complex bronchitis" with repeated chest illnesses and breathlessness is more common among older men in this country. After differences in age distribution and smoking habits have been taken into account, this form of bronchitis appears to be about equally common in the American town and in the rural areas of Britain. It is much more common, however, in the British towns and cities, especially among men.

The results of the lung-function test are consistent with this suggestion of a higher prevalence of a more severe form of bronchitis among older males living in British urban conditions. The causes of this excess are still uncertain.

This investigation was supported in whole by U.S. Public Health Service Grant HE 04775-03 from the National Heart Institute. The original studies were supported by the Dominion of Canada National Health Research Grant (Project No. 609-7-73), the United States Public Health Service Research Grant (OH-67), and the Nuffield Provincial Hospitals Trust. The College of General Practitioners has kindly allowed us to use the data collected by members of their College for the Respiratory Diseases Study Group. We are indebted to Miss Elizabeth Farrow for the computations involved.

\section{REFERENCES}

Anderson, D. O., and Ferris, B. G. (1962). New Engl. F. Med., 267, 787. College of General Practitioners (1961). Brit. med. F., 2, 973. Ferris, B. G., and Anderson, D. O. (1962). Amer. Rev. resp. Dis., 86, 165.

Fletcher, C. M., Elmes, P. C., Fairbairn, A. S., and Wood, C. H. (1959). Brit. med. $7 ., 2,257$.

Hammond, E. C., and Garfinkel, L. (1961). 7. nat. Cancer Inst., 27, 419. Higgins, I. T. T. (1957). Brit. med. f., 2, 1198.

Meneely, G. R., Paul, O., Dorn, H. F., and Harrison, T. R. (1960). F. Amer. med. Ass., 174, 1628.
Ameely, G. R., Paul, O., Dorn,

Olsen, H. C., and Gilson, J. C. (1960). Brit. med. f., 1, 450.

Reid, D.'D.' (1960). Amer. 7. publ. Hlth, 50, 53

Todd, G. F. (1963). Research Paper No. 6. Tobacco Research Council, London.

\title{
Comparison of Lymecycline with Tetracycline Hydrochloride
}

\author{
J. L. WHITBY,* M.B., M.R.C.P., M.C.PATH. ; H. J. BLACK,* M.B., B.CH.
}

Brit. med. F., 1964, 2, 1491-1495

Lymecycline (tetracycline-L-methylenelysine ; Tetralysal) is a tetracycline-amino-acid compound obtained by combining tetracycline base with L-lysine in the presence of formaldehyde. Its formula (de Carneri and Manfredi, 1962) gives a molecular weight for the pure substance of 602.7 , while the molecular weight of tetracycline hydrochloride is 480.9 and the drugs are equivalated in this ratio. It may have certain advantages over tetracycline hydrochloride in that its solubility, particularly in water, is much greater than that of other tetracyclines (de Carneri et al., 1961), and it has been claimed that it is absorbed more completely than tetracycline hydrochloride from the gastro-intestinal tract. It is also suitable for intramuscular injection. We here report the results of a clinical trial of this compound. In this trial blood levels after oral lymecycline were compared with those following tetracycline hydrochloride and

* From the Department of Clinical Pathology, Queen Elizabeth Hospital, Birmingham. the incidence of side-effects in patients after the use of these drugs was also compared.

\section{Materials and Methods}

Antibiotics. - Tetracycline hydrochloride B.P. as obtained from the pharmacy of the Queen Elizabeth Hospital was used as a reference standard. A preparation of lymecycline powder was supplied by Messrs. Carlo Erba ; biological assay in Italy of their preparation had shown $1 \mathrm{~g}$. of the lymecycline powder to be equivalent to $0.6056 \mathrm{~g}$. of tetracycline base or $0.6553 \mathrm{~g}$. of tetracycline hydrochloride. From these materials standards were made up for antibiotic assays throughout the trial.

Antibiotic assays were performed by a cylinder-plate method in the following manner. A measured $6 \mathrm{ml}$. of nutrient agar was added to $9-\mathrm{cm}$. disposable plastic Petri dishes which were 